Research report

\title{
Pharmacological characterization of the nociceptin/orphanin FQ receptor on ethanol-mediated motivational effects in infant and adolescent rats
}

\author{
Roberto Sebastián Miranda-Morales ${ }^{a, *}$, Ricardo M. Pautassi ${ }^{a, b}$ \\ a Instituto de Investigación Médica Mercedes y Martín Ferreyra (INIMEC-CONICET-Universidad Nacional de Córdoba), 5016 Córdoba, Argentina \\ ${ }^{\mathrm{b}}$ Facultad de Psicología, Universidad Nacional de Córdoba, 5000 Córdoba, Argentina
}

\section{H I G H L I G H T S}

- Infant and adolescent rats are sensitive to ethanol's reinforcing properties.

- Activation of NOP receptors did not alter ethanol-induced CTA.

- Activation of NOP receptors did not alter ethanol intake patterns in adolescents.

- Activation of NOP receptors attenuated ethanol-induced anxiolysis in adolescents.

- Activation of NOP receptors inhibited ethanol's stimulating effects in adolescents.

\section{A R T I C L E I N F O}

\section{Article history:}

Received 13 January 2015

Received in revised form 9 April 2015

Accepted 10 April 2015

Available online 20 April 2015

\section{Keywords:}

Ethanol anxiolytic effect

Ethanol-induced locomotor activation

Early ontogeny

NOP opioid receptor

\begin{abstract}
A B S T R A C T
Activation of nociceptin/orphanin FQ (NOP) receptors attenuates ethanol drinking and prevents relapse in adult rodents. In younger rodents (i.e., infant rats), activation of NOP receptors blocks ethanol-induced locomotor activation but does not attenuate ethanol intake. The aim of the present study was to extend the analysis of NOP modulation of ethanol's effects during early ontogeny. Aversive and anxiolytic effects of ethanol were measured in infant and adolescent rats via conditioned taste aversion and the light-dark box test; whereas ethanol-induced locomotor activity and ethanol intake was measured in adolescents only. Before these tests, infant rats were treated with the natural ligand of NOP receptors, nociceptin $(0.0,0.5$ or $1.0 \mu \mathrm{g})$ and adolescent rats were treated with the specific agonist Ro $64-6198(0.0,0.1$ or $0.3 \mathrm{mg} / \mathrm{kg}$ ). The activation of NOP receptors attenuated ethanol-induced anxiolysis in adolescents only, and had no effect on ethanol's aversive effects. Administration of Ro 64-6198 blocked ethanol-induced locomotor activation but did not modify ethanol intake patterns. The attenuation of ethanol stimulating and anxiolytic effect by activation of NOP receptors indicates a modulatory role of this receptor on ethanol effects, which is expressed early in ontogeny.
\end{abstract}

(C) 2015 Elsevier B.V. All rights reserved.

\section{Introduction}

Ethanol reinforcement and acceptance is regulated, at least partly, by the endogenous opioid system [1]. Four major classes of opioid receptors, widely distributed in brain areas associated with ethanol's reinforcing effects [2], have been identified: $\mu, \delta, \kappa$, and the nociceptin/orphanin FQ peptide (NOP) receptor [3,4].

\footnotetext{
* Corresponding author at: Instituto de Investigación Médica M. y M. Ferreyra, Friuli 2434, 5016 Córdoba, Argentina. Tel.: +54 0351 4681465x202; fax: +5403514695163.

E-mail address: smiranda@immf.uncor.edu (R.S. Miranda-Morales).
}

In the last decade, several studies have indicated that ethanol exposure during infancy and adolescence promotes subsequent ethanol seeking and drinking $[5,6]$. Some of these studies have focused on the modulatory role exerted by the opioid receptors on ethanol reinforcement. It has been shown that non-specific opioid antagonists co-administered with ethanol during gestation disrupt appetitive responding toward ethanol $[7,8]$. Furthermore, prenatal blockade of the $\mu$-opioid receptors completely inhibited the promoting effect of prenatal ethanol on ethanol intake and palatability, while $\kappa$ antagonism only partially reduced the palatability effect [9].

Selective $\mu$ and $\kappa$ antagonists inhibit ethanol-induced reinforcement in preweanling rats [10] whereas $\mu$ or $\delta$ (but not $\kappa$ ) opioid antagonism drastically reduces ethanol intake [11]. Pautassi et al. 
[12] observed that blockade of $\kappa$ function facilitated conditioned place and taste preference induced by ethanol, a result consistent with the notion that the aversive effects of ethanol may be mediated in part by activation of $\kappa$ receptors. According to this hypothesis, manipulations that reduce the function of $\kappa$ receptors in nondependent subjects should attenuate the aversive consequences of ethanol and promote the expression of appetitive reinforcement [12]. The $\mu$ receptor is also involved in ethanol-mediated locomotor stimulation, which is considered a proxy for ethanol's reinforcing effects. Blockade of $\mu$, but not $\delta$ or $\kappa$ receptors, attenuates ethanol-induced locomotor activation [11]. Prenatal ethanol exposure during late gestation also seems to affect $\kappa$ function and expression; the offspring of dams treated with ethanol during gestational days 17-20 exhibited either no aversion or appetitive responding to $\kappa$ activation, while control subjects found $\kappa$ opioid activation aversive. Furthermore, $\kappa$ opioid receptor expression after prenatal ethanol was decreased in brain areas implicated in the motivational effects of the drug [13]. A recent study in infant rats indicates the participation of $\mu, \delta$ and $\kappa$ receptors in ethanol operant self-administration [14].

Most of the studies analyzing NOP modulation of ethanol reinforcement have employed adult rats, often from strains genetically selected for high ethanol preference [15]. The modulatory role of the NOP receptor on ethanol reinforcement during early ontogeny has been much less studied and, to our knowledge, only one study has focused on this issue [16]. The NOP receptor can be detected as early as gestational day 12 in the rat and is observed at 16 weeks of gestation in humans [17]. After the first 2 weeks of postnatal life in the rat, NOP mRNA expression and distribution is similar to those observed in the adult brain [17]. Nociceptin/orphanin FQ (hereafter referred to as "nociceptin"), the endogenous ligand for NOP receptor, binds with high affinity to the NOP receptor, but does not activate classic opioid receptors ( $\mu, \delta$ or $\kappa$ ) [18]. A still limited amount of evidence suggests that NOP may modulate ethanol's motivational properties. Nociceptin and other NOP agonists decrease alcohol drinking and prevent relapse in rats [19-23]; and also inhibit reinforcement induced by morphine [24], cocaine, and amphetamine $[25,26]$.

There is scarce information concerning the role of NOP receptors on ethanol's motivational effects during early ontogeny. Previously, we found [16] that nociceptin blocked ethanol-induced locomotor activation but did not affect ethanol intake, in 2-week old Sprague-Dawley rats. The study of the neurobiological basis of ethanol-mediated reinforcement in infancy is important when taking into account that the onset of ethanol initiation is quickly descending worldwide. A birth cohort study, for instance, indicated that almost $20 \%$ of a sample of Brazilian children aged 11-12 years had already experimented with ethanol [27], and a recent study conducted in Argentina [28] indicated ethanol sipping and tasting in $58 \%$ of its sample $(n=367)$ of 8 to 12 -year-old children. A similar study highlighted that $37 \%$ of 8 -year-old North American children have already tasted ethanol and the frequency increased to $67 \%$ in 12 -year-old children [29]. These early ethanol experiences could facilitate subsequent engagement with the drug during adolescence, which in turn significantly enhances the possibilities of abuse and dependence later in life. Adolescence is a developmental stage in which rats exhibit altered sensitivity to several effects of ethanol. For example, adolescents are - when compared to adults - more sensitive to ethanol stimulating effects [30] and less sensitive to ethanol motor-sedative effects $[6,30]$. These differences have been proposed to reflect greater ethanol-induced appetitive reinforcement in younger individuals, which may underlie their propensity to engage in ethanol self-administration.

The aim of the present study was to extend our previous analysis of NOP modulation of ethanol's effects [16]. Specifically, we measured aversive and anxiolytic effects of ethanol in
Table 1

Number of animals employed for each experiment

\begin{tabular}{lll}
\hline \multirow{2}{*}{ Experiment } & \multicolumn{2}{l}{ Number of animals } \\
\cline { 2 - 3 } & Males & Females \\
\hline 1a. CTA in infants & 25 & 25 \\
1b. CTA in adolescents & 38 & 40 \\
2a. LDB in infants & 47 & 53 \\
2b. LDB in adolescents & 63 & 53 \\
3. LMA in adolescents & 57 & 48 \\
4. Intake test in adolescents & 26 & 30 \\
\hline
\end{tabular}

infant and adolescent rats, via conditioned taste aversion and the light-dark box test (CTA and LDB, respectively); whereas ethanolinduced locomotor activity (LMA) and ethanol intake was measured in adolescents only. Across these measurements, subjects were administered ethanol alone or in conjunction with a NOP agonist. NOP modulation of ethanol-induced LMA and ethanol intake in infant rats were not tested in the present study because these variables had been already analyzed in a previous study (see [16]). This study will help make progress toward understanding the neural mechanisms by which ethanol exerts appetitive, aversive and anti-anxiety effects during early stages of development.

\section{General methods}

\subsection{Subjects}

A total of 156 infant (PDs 14-17) and 347 adolescent (PDs 29-36) Wistar rats were used across experiments [Experiment 1a (CTA in infants): 56 animals derived from 9 litters; Experiment $1 \mathrm{~b}$ (CTA in adolescents): 70 animals derived from 9 litters; Experiment 2a (LDB in infants): 100 animals derived from 15 litters; Experiment $2 \mathrm{~b}$ (LDB in adolescents): 116 animals derived from 14 litters; Experiment 3 (LMA in adolescents): 105 animals derived from 12 litters; Experiment 4 (intake test in adolescents): 56 animals derived from 7 litters]. The number of animals (disaggregated by sex: male or female) employed in each experiment are detailed in Table 1 . These animals were born and reared in the vivarium of the Instituto M. M. Ferreyra (INIMEC-CONICET-Universidad Nacional de Córdoba, Córdoba, Argentina). Births were examined daily, and the day of birth was considered PD 0 . On PD 1, litters were culled to 10 pups (five males and five females, whenever possible). Pups were housed with the dam in standard maternity cages with free access to water and food. On PD 21, animals were weaned from the dam and housed in same-sex groups. The colony was maintained at $22 \pm 1^{\circ} \mathrm{C}$ under a $12 / 12 \mathrm{~h}$ light/dark cycle. The experiments were approved by the Ministry of Animal Care of INIMEC-CONICET-UNC and were in compliance with the NIH Guide for the Care and Use of Laboratory Animals [31].

\subsection{Drug preparation and administration procedures}

The NOP endogenous ligand, nociceptin (TOCRIS, Ellisville, MO) was employed at doses of $0.0,0.5$, or $1.0 \mu \mathrm{g} / \mathrm{rat}$, in the two experiments with infant rats (Experiments 1a and 2a: CTA and LDB tests, respectively). Nociceptin was dissolved in saline $(\mathrm{NaCl} 0.9 \% \mathrm{v} / \mathrm{v})$ and injected in a volume of $2 \mu \mathrm{l} / \mathrm{rat}$, into the cisterna magna (IC) and using a 30-gauge hypodermic needle attached to a length of polyethylene tubing (PE-10). The needle was inserted under visual guidance into the foramen magnum between the occipital bone and the first cervical vertebra [32,33]. Successful placement of the needle into the target site was confirmed by the appearance of cerebrospinal fluid in the tubing. Nociceptin was injected in a 5-s pulse with a micrometer gastight syringe (Hewlett-Packard, USA). This volume of infusion does not seem to cause any discomfort or 
distress and is not excessive for an infant rat, which weighs 30-35 g. In both Experiments 1a and 2a the infants were tested 10 min after nociceptin injection, to allow them recover from the intracisternal administration.

The NOP agonist Ro 64-6198 ((1S,3aS)-8-(2,3,3a,4,5,6Hexahydro-1H-phenalen-1-yl)-1-phenyl-1,3,8-triaza-spiro[4.5] decan-4-one hydrochloride, MW 438.017), a gift of Dr. Eric Prinssen (F. Hoffmann-La Roche Ltd, Pharma Preclinical Research, Basel, Switzerland), was employed at doses $0.0,0.1$, or $0.3 \mathrm{mg} / \mathrm{kg}$, in the experiments that used adolescent animals (i.e., Experiments $1 \mathrm{~b}, 2 \mathrm{~b}, 3$ and 4 ). This drug was dissolved in a solution of saline and $0.25 \%$ acetic acid, and intraperitoneally injected at a volume of $0.01 \mathrm{ml} / \mathrm{g}$. The advantage of using Ro 64-6198 over nociceptin in older animals is that Ro 64-6198 can be administered via intraperitoneal (i.p.) injection. Due to technical drawbacks, the use of the IC mode of administration becomes very difficult in rats aged 20 days or older. This alternative, avoids the implantation of cannulas in the adolescent brain through stereotaxic surgery, the ensuing manipulation and stress, to facilitate comparisons across age. This non-peptide agonist binds NOP receptors with an affinity similar to that of the natural ligand nociceptin; in addition, the agonist displays similar pEC50, Emax and pKB values in the rat to those exhibited by nociceptin [34]. Adolescents were evaluated 30 min after Ro 64-6198 injection [35].

\subsection{Test of conditioned taste aversion}

The Experiments $1 \mathrm{a}$ and $1 \mathrm{~b}$ analyzed, through conditioned taste aversion, if activation of NOP receptors altered the aversive properties of ethanol. Access to a $0.1 \%$ saccharin solution (conditioned stimulus, CS; Parker Davis, Argentina) was paired (P groups) with the post-ingestive effects of a high ethanol dose (unconditional stimulus, US). Animals were administered nociceptin (infants) or Ro 64-6198 (adolescents) before daily conditioning sessions. In each session animals drank the saccharin solution (CS) and immediately after were administered $2.5 \mathrm{~g} / \mathrm{kg}$ ethanol (US). An unpaired (UP) control group received ethanol 2-h after saccharin intake, thus preventing an association between CS and US. Animals were given two (infants) or one (adolescents) conditioning sessions, and then two extinction trials were performed.

In Experiment 1a, infant rats were given two sessions of conditioning (one daily, PDs 14-15) and two test sessions (PDs 16-17). During these tests, the animals were exposed to the CS, but had no injection of nociceptin or ethanol. Across all sessions, saccharin was given through intraoral cannulas implanted in the animal's cheek (for a detailed description of this procedure please see $[8,16]$ ). The pups experienced 120 min of maternal separation before commencement of each session. Subsequently, they were assigned to the experimental treatments defined by the pairing (or not) between US-CS and the different doses of nociceptin. Before conditioning trials, pups' bladders were voided by gentle brushing of the anogenital area. Body weights were subsequently registered and nociceptin was administered. The mean weight of the subjects was calculated and used as a benchmark for the volume of the intraoral infusion of saccharin. The total volume administered to each subject was equivalent to $3 \%$ of their body weight and was infused at a constant rate for $15 \mathrm{~min}$. These parameters allow pups to either accept or reject the infused solution. Each subject's cannula was connected to a length of PE50 tubing that in turn was connected to a $10 \mathrm{ml}$ syringe operated by an automatic infusion pump (KD Scientific, Holliston, MA). The subjects were placed into Plexiglas containers measuring $9 \mathrm{~cm} \times 15 \mathrm{~cm}$. The bottoms of these containers were lined with absorbent paper. Immediately following the intraoral infusion, pups were disconnected from the tubing, weighed, and administered intragastrically with ethanol (only the paired group). After administration of ethanol to the unpaired control group, animals were returned to their dams.

During the two test trials, subjects had the same manipulation as during conditioning trials, but received no administration of nociceptin or ethanol. Consumption of saccharin during conditioning and test was calculated as follows: ([(post-test weight - pre-test weight)/pre-test weight] $\times 100$ ) .

In Experiment $1 \mathrm{~b}$, adolescent animals were same-sex pairhoused. Homecages were divided in two equal spaces where each animal was placed. Animals could see or smell each other through the plastic divider. In order to avoid a possible latent inhibition effect, the conditioning trial was shorter than the test trials (30 and 60 min, respectively). During conditioning on PD 31, animals were i.p. injected with Ro 64-6198 and, 30 min later, were given 30-min access to a graduated glass tube filled with saccharin. Immediately after the intake test, animals were i.p. injected with ethanol. Two test trials (one per day, PDs 33-34) of 60 min were conducted. The rest day, which was also employed in other CTA studies (see $[38,39])$, was meant to minimize the effect of partial water deprivation during conditioning. Animals had access to a tube filled with $0.1 \%$ saccharin, in the absence of the US or RO-64-6198 injection. Across conditioning and test sessions and to motivate CS consumption, animals had access to 50\% of their normal ingestion of water. The dependent variable employed was milliliters of saccharin consumed per $100 \mathrm{~g}$ of body weight $(\mathrm{ml} / 100 \mathrm{~g})$.

Different routes of ethanol administration were used to induce conditioned taste aversion in infant and adolescent rats (i.g. vs. i.p., respectively). We followed the procedures of studies that had reliably found ethanol-induced conditioned taste aversion at these ages. The i.p. route has been traditionally used in adolescent studies (see [39]), whereas the i.g. administration has been preferred in studies with infant rats (for instance please see $[40,41]$ ).

\subsection{Light/dark test}

In Experiment 2, infant (PD16) and adolescent (PD34) rats were evaluated for anxiety response in a 5-min light-dark box test. The apparatus $(42 \mathrm{~cm} \times 25 \mathrm{~cm} \times 25 \mathrm{~cm})$ featured two compartments made of high impact acrylic, one white $(24.5 \mathrm{~cm} \times 25 \mathrm{~cm} \times 25 \mathrm{~cm})$ illuminated by a $60 \mathrm{~W}$ white bulb lamp that was adjusted to generate an illumination level of 400 lux, and one black $(17.5 \mathrm{~cm} \times 25 \mathrm{~cm} \times 25 \mathrm{~cm})$ with no illumination (0 lux). Illumination of the apparatus was measured via a digital lux meter (LX1010B). A divider with an opening at floor level separated both compartments. Animals were administered nociceptin (infants, Experiment 2a) or Ro 64-6198 (adolescents, Experiment 2b) 10- or 30 -min before they were intubated with ethanol $(0.0$ or $0.5 \mathrm{~g} / \mathrm{kg}$ ). This dose of ethanol has been previously shown to exert anxiolytic effects in both infant and adolescent rats [36,37]. The test began 5 min after ethanol administration by gently placing the animal in the center of the white area, facing away from the black area. Immediately after termination of the 5-min test, animals were removed and returned to homecage. The behavior was filmed (SONY Handycam HD AVCHD) and subsequently processed by an observer unaware of the experimental conditions. The variables analyzed were time (s) spent in the illuminated area, latency (s) to enter into the dark area, number (frequency) of transfer between compartments.

\subsection{Adolescent locomotor activity assessment}

In Experiment 3, adolescent rats were evaluated at PD34 in an open field to test ethanol-induced locomotor activation and modulation of NOP receptors of this effect. The animals were injected with Ro 64-6198 and 30-min later intubated with ethanol (0.0 or $2.5 \mathrm{~g} / \mathrm{kg}$ ). Following intubation, subjects were returned to a 
holding cage lined with pine shavings. Five minutes after the intubation, animals were tested for $8 \mathrm{~min}$ (i.e., post-administration time $5-12 \mathrm{~min})$ in square chambers $(60 \mathrm{~cm} \times 60 \mathrm{~cm} \times 60 \mathrm{~cm})$. Previous studies [38] indicate that adolescent Wistar rats exhibit motor stimulation after $2.5 \mathrm{~g} / \mathrm{kg}$ ethanol, which is the same dose that was used to generate conditioned aversion (see Section 2.3). Although this may seem paradoxical, it should be noted that ethanol - particularly at high doses -- has biphasic effects during the course of the intoxication. Appetitive and motor activating effects seem to prevail shortly after ethanol administration (5-20 min) while aversive effects are more prevalent during later post-administration times [42].

Motor activity was measured using automatized chambers (ITCOMM, Córdoba, Argentina) that tracked the rat's movement in a real-time basis and recorded distance traveled $(\mathrm{cm})$ during the test. Testing was conducted under moderate to dim light. The apparatus was cleaned with a sponge that was soaked with water between each test.

\subsection{Adolescent homecage ethanol consumption test}

Experiment 4 tested voluntary ethanol consumption using a modified test of a standardized two-bottle ethanol intake protocol $[42,43]$. Animals underwent daily 2 -h intake sessions (PDs 33-36), preceded by $22 \mathrm{~h}$ in which they had access to $50 \%$ of the water they usually consume. On PD31, adolescent animals were samesex pair-housed. Each homecage was divided in two equal spaces where each animal was placed. Animals could see and smell each other through the plastic divider. In this first day of the experiment, the animals were weighed and they had access to a $50 \mathrm{ml}$ bottle filled with tap water. Twenty-four hours later, on PD32, bottles were refilled with $50 \%$ of the water that the animal would regularly drink, according to pilot studies conducted with rats of that age. On PDs 33-36, 30 min before commencement of the each daily 2-hour intake session, the rats were injected with Ro 64-6198, at the doses detailed before. During drinking sessions, the animals had access to two graded $25 \mathrm{ml}$ tubes, one filled with tap water and the other with the ethanol solution $(3 \% \mathrm{v} / \mathrm{v}$ on PD33, $4 \%$ on PD34, and 5\% on PDs 35-36). The volume consumed from each tube was assessed 20,60 and 120 min after commencement of each test. Tubes were never touched or removed during intake tests. The position of the ethanol and water tubes was varied across sessions to prevent place-preference effects. After each intake session the tubes were removed and replaced with a bottle filled with $50 \%$ of the water that the animal would regularly drink. The dependent variables were ethanol intake in grams per kilogram $(\mathrm{g} / \mathrm{kg})$ and percent selection of ethanol [(consumption of ethanol/overall liquid ingestion $) \times 100$ ]. This intake protocol has been extensively used to detect the influence of early alcohol exposure, mediated by maternal consumption during breastfeeding [43], operant selfadministration [42] or passive intubations [38], on later alcohol acceptance.

\subsection{Experimental design and data analysis}

Across experiments, no more than one subject from each sex was assigned to the same treatment condition in a given litter. Experiment 1a (CTA test) employed a 3 (nociceptin dose: 0.0, 0.5, or $1.0 \mu \mathrm{g}) \times 2$ (conditioning: paired or unpaired) $\times 2$ (sex: male or female) factorial design. Experiment $1 \mathrm{~b}$ (CTA test) employed a 3 (Ro 64-6198 dose: $0.0,0.1$, or $0.3 \mathrm{mg} / \mathrm{kg}$ ) $\times 2$ (conditioning: paired or unpaired) $\times 2$ (sex: male or female) factorial design. Experiment 2 (LDB test) employed a 3 (nociceptin dose: $0.0,0.5$, or $1.0 \mu \mathrm{g}) \times 2$ (ethanol dose: 0.0 or $0.5 \mathrm{~g} / \mathrm{kg}) \times 2$ (sex: male or female) factorial design for infants and a 3 (Ro 64-6198 dose: 0.0, 0.1, or $0.3 \mathrm{mg} / \mathrm{kg}) \times 2$ (ethanol dose: 0.0 or $0.5 \mathrm{~g} / \mathrm{kg}) \times 2$ (sex: male or female) factorial design for adolescents. Experiment 3 (Locomotor Activity Assessment) employed a 3 (Ro 64-6198 dose: 0.0, 0.1, or $0.3 \mathrm{mg} / \mathrm{kg}) \times 2$ (ethanol dose: 0.0 or $2.5 \mathrm{~g} / \mathrm{kg}) \times 2$ (sex: male or female) factorial design. Experiment 4 (Ethanol Consumption Test) employed a 3 (Ro $64-6198$ dose: $0.0,0.1$, or $0.3 \mathrm{mg} / \mathrm{kg}$ ) $\times 2$ (sex: male or female) factorial design.

Data obtained from the four experiments were analyzed with Analysis of variance (ANOVA) that eventually involved repeated measures. In Experiment 1b, conditioning and extinctions sessions differed in length (30 and $60 \mathrm{~min}$, respectively). Therefore, two independent ANOVAs were executed on saccharin intake data in adolescents. The loci of significant main effects or multiple interactions were analyzed with Fisher's LSD post hoc comparisons. A rejection criterion of $p<0.05$ was adopted for all statistical analysis in the present study.

\section{Results}

Experiment 1a (CTA in infants). Saccharin intake data was analyzed through a 4-way mixed (between-subjects factors: Conditioning, Nociceptin treatment and Sex; Days of evaluation was the within factor) ANOVA. The analysis yielded a significant main effect of Days of evaluation $[F(3,114)=39.03, p<0.001]$ and a significant days of evaluation $\times$ conditioning interaction $[F(3,114)=4.91$, $p<0.01]$. Fisher LSD post hoc tests revealed similar saccharin acceptance during conditioning days in P and UP groups. During extinction test trials, however, $P$ animals exhibited significantly lower intake scores than UP animals ( $p$ 's $<0.001$ ). No significant main effect or significant interaction compromising nociceptin or sex was observed.

Experiment $1 \mathrm{~b}$ (CTA in adolescents). The ANOVA conducted for saccharin scores during conditioning (between-subjects factors: Ro 64-6198 treatment, conditioning and sex) indicated no significant main effects or significant interactions. For the test trials, the mixed ANOVA indicated significant main effects of days of evaluation and conditioning $[F(1,58)=81.03, p<0.001$ and $F(1$, $58)=6.37, p<0.025$, respectively]. Animals consumed significantly more saccharin during the second than during the first test trial and, perhaps more important, paired animals consumed significantly less saccharin than UP control adolescent rats. No significant effect of the NOP agonist or interaction with the other factors was observed.

In summary, infant and adolescent rats were sensitive to the aversive effects of a high ethanol dose. Activation of NOP receptors, nonetheless, did not modify the intensity of aversion to ethanol. These results are summarized in Table 2.

Experiment $2 a$ (LDB in infants). The ANOVAs (between-subjects factors: Nociceptin treatment, ethanol treatment and sex) for time spent in the illuminated area and latency to enter into the dark area indicated neither significant main effect nor significant interactions. Frequency of transfer between compartments was significantly affected by Ethanol treatment $[F(1,88)=4.51, p<0.05]$. Administration of $0.5 \mathrm{~g} / \mathrm{kg}$ ethanol significantly increased the number of transfers between compartments, yet this effect was similar in animals administered either dose of nociceptin or vehicle.

Experiment $2 b$ ( $L D B$ in adolescents). In adolescent animals, the factorial ANOVA on time spent in the illuminated area (between factors: Ro 64-6198 treatment, ethanol treatment and sex) indicated a significant interaction of ethanol $\times$ Ro 64-6198 treatments $[F(2,65)=3.87, p<0.05]$. LSD post hoc tests showed that animals treated with $0.5 \mathrm{~g} / \mathrm{kg}$ ethanol and saline spent significantly more time in the white area than the remaining control groups (waterintubated and injected with $0.0,0.1$ or $0.3 \mathrm{mg} / \mathrm{kg}$ Ro $64-6198$ ). The post hoc tests also indicated that administration of the NOP agonist at $0.1 \mathrm{mg} / \mathrm{kg}$ completely blocked the anxiolytic effect of ethanol 
Table 2a

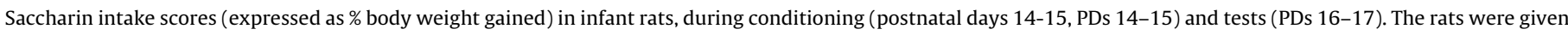

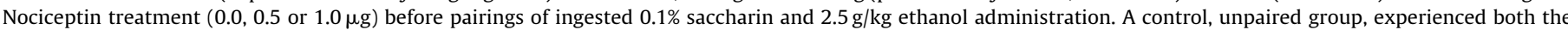

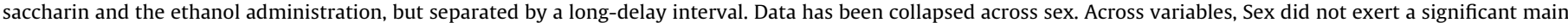
effect nor was involved in significant interactions. Values are expressed as mean \pm SEM.

\begin{tabular}{|c|c|c|c|c|c|}
\hline \multirow[t]{2}{*}{ Nociceptin dose } & \multirow[t]{2}{*}{ Conditioning group } & \multicolumn{4}{|c|}{ Saccharin intake } \\
\hline & & PD14 & PD15 & PD16 & PD17 \\
\hline \multirow{2}{*}{$0.0 \mu \mathrm{g}$} & Paired & $0.67 \pm 0.14$ & $0.95 \pm 0.16$ & $0.80 \pm 0.13$ & $1.38 \pm 0.22$ \\
\hline & Unpaired & $0.84 \pm 0.12$ & $0.96 \pm 0.08$ & $1.36 \pm 0.21$ & $2.15 \pm 0.27$ \\
\hline \multirow{2}{*}{$0.5 \mu \mathrm{g}$} & Paired & $0.87 \pm 0.12$ & $1.16 \pm 0.18$ & $0.96 \pm 0.15$ & $1.39 \pm 0.24$ \\
\hline & Unpaired & $0.73 \pm 0.12$ & $0.73 \pm 0.08$ & $1.24 \pm 0.17$ & $1.78 \pm 0.22$ \\
\hline \multirow{2}{*}{$1.0 \mu \mathrm{g}$} & Paired & $0.91 \pm 0.16$ & $1.06 \pm 0.17$ & $1.17 \pm 0.20$ & $1.68 \pm 0.30$ \\
\hline & Unpaired & $0.81 \pm 0.08$ & $0.83 \pm 0.14$ & $1.29 \pm 0.23$ & $1.83 \pm 0.30$ \\
\hline
\end{tabular}

( $p<0.01$ ). The $0.3 \mathrm{mg} / \mathrm{kg}$ dose of Ro 64-6198 also seemed to attenuate ethanol-induced anxiolysis, yet the post hoc neared but did not achieve significance $(p=0.07)$. Control (water intubated) animals did not significantly differ from each other, regardless of treatment with Ro 64-6198.

The ANOVA for latency of enter into the dark area only yielded a borderline ethanol $\times$ Ro 64-6198 treatment interaction $[F(2$, $65)=2.81, p=0.067]$. The overall profile of response was similar to that observed for time spent in the illuminated area.

The animals treated with $0.1 \mathrm{mg} / \mathrm{kg}$ Ro 64-6198 did not exhibit emergences from the dark area (i.e., means for these groups were $0.0 \pm 0.0$ ). Therefore, a non-parametric analysis was used to analyze this variable. The Kruskal-Wallis test indicated that frequency of emergence was significantly affected by Ro 64-6198 treatment $[H(2,116)=9.44, p<0.01]$. Administration of NOP agonist at $0.1 \mathrm{mg} / \mathrm{kg}$ drastically inhibited the number of transfers between compartments. Ethanol treatment or sex did not significantly affect the frequency of emergence from the dark area.

Overall, the results indicate that animals tested in the LDB exhibit ethanol-induced anxiolysis, particularly during adolescence. More important, this effect of ethanol was abolished when NOP receptors were pharmacology activated during adolescence. Ro 64-6198 at $0.1 \mathrm{mg} / \mathrm{kg}$ seemed to exert effects by its own evidenced as a significant attenuation of exploratory behavior between illuminated and dark area. Results of Experiments 2a and 2b are summarized in Figs. 1 and 2, respectively.

Experiment 3 (LMA in adolescents). A preliminary, one-way ANOVA (comparative factor between groups: Ro 64-6198 treatment) was conducted on water-intubated animals to analyze possible effects of Ro 64-6198 on basal locomotor activity. This analysis indicated no significant main effects of the agonist ( $p \square 0.65$ ). Therefore, for subsequent analyses the water-treated groups were collapsed across nociceptin treatment in a single control condition. Ethanol-induced locomotor activity was then

\section{Table 2b}

Saccharin intake scores (expressed as $\mathrm{ml} / 100 \mathrm{~g}$ ) in adolescent rats during conditioning (postnatal day 31, PD 31) and test (PDs 33-34). The rats were given Ro 64-6198 treatment $(0.0,0.1$ or $0.3 \mathrm{mg} / \mathrm{kg})$ before pairings of ingested $0.1 \%$ saccharin and $2.5 \mathrm{~g} / \mathrm{kg}$ ethanol administration. A control, unpaired group, experienced both the saccharin and the ethanol administration, but separated by a long-delay interval. Data has been collapsed across sex. Across variables, Sex did not exert a significant main effect nor was involved in significant interactions Values are expressed as mean \pm SEM.

\begin{tabular}{lllll}
\hline \multirow{2}{*}{$\begin{array}{l}\text { Ro 64-6198 } \\
\text { dose }\end{array}$} & $\begin{array}{l}\text { Conditioning } \\
\text { group }\end{array}$ & \multicolumn{2}{l}{ Saccharin intake } \\
\cline { 3 - 5 } & & PD31 & PD33 & PD34 \\
\hline \multirow{2}{*}{$0.0 \mathrm{mg} / \mathrm{kg}$} & Paired & $3.93 \pm 0.50$ & $3.03 \pm 0.57$ & $6.04 \pm 0.77$ \\
& Unpaired & $3.12 \pm 0.38$ & $5.62 \pm 0.48$ & $7.62 \pm 0.56$ \\
$0.1 \mathrm{mg} / \mathrm{kg}$ & Paired & $3.89 \pm 0.59$ & $3.14 \pm 0.64$ & $5.59 \pm 0.92$ \\
& Unpaired & $3.54 \pm 0.59$ & $5.18 \pm 0.61$ & $7.60 \pm 0.68$ \\
$0.3 \mathrm{mg} / \mathrm{kg}$ & Paired & $4.74 \pm 0.63$ & $3.80 \pm 0.80$ & $5.92 \pm 0.92$ \\
& Unpaired & $3.32 \pm 0.35$ & $3.99 \pm 0.73$ & $6.94 \pm 1.16$ \\
\hline
\end{tabular}

analyzed through a two-way ANOVA which included the factors sex (male or female) and Ro 64-6198 treatment [control, 0.0 + ethanol, $0.1+$ ethanol, $0.3+$ ethanol; the number before ethanol indicates the dose of Ro 64-6198 (mg/kg) administered]. The ANOVA indicated significant main effects of both Sex and Ro 64-6198 treatment $[F(1,97)=4.0, p<0.05$ and $F(3,97)=10.7, p<0.001$, respectively $]$. Adolescent females displayed significantly greater locomotor activity than males' counterparts. Of major importance, administration of ethanol before testing (i.e., $0.0+$ ethanol group) induced significantly greater locomotor activity than administration of water (i.e., water-control group) ( $p<0.001)$. In addition, Ro 64-6198 at $0.1 \mathrm{mg} / \mathrm{kg}$ attenuated ethanol's motor stimulating effects: animals in the $0.1+$ ethanol group displayed significantly lower motor activity scores than animals in the $0.0+$ ethanol group $(p<0.01)$ and were not significantly different from water-control animals. The agonist at $0.3 \mathrm{mg} / \mathrm{kg}$ did not show any effect on ethanol's stimulant effects: the locomotor activity of these animals was similar to that exhibited by animals in group $0.0+$ ethanol $(p=0.47)$ and significantly higher than the water-control group $(p<0.001)$. These results are summarized in Fig. 3.

Overall, results from Experiment 3 indicated that the activation of NOP receptors attenuate ethanol-induced locomotor stimulation, a result not attributable to unspecific motor stimulating or depressing effects of the agonist on basal locomotor activity.

Experiment 4 (Adolescent ethanol consumption test). The ANOVA for overall intake scores $(\mathrm{ml} / 100 \mathrm{~g}$ consumed of ethanol + water) considered Ro 64-6198 treatment and sex as between-subjects factors and days of evaluation as the repeated measures factor. The ANOVA indicated a significant main effect of days of evaluation $[F(3,150)=10.51, p<0.001]$. The adolescents significantly increased their overall intake in the third day of evaluation, compared to days 1 and 2, $(p<0.001)$ and kept this relatively high level of consumption during the fourth day. This main effect of days of evaluation was also found to be significant when analyzing water intake and ethanol intake $[F(3,150)=6.5, p<0.001 ; F(3,150)=9.18, p<0.001$, respectively]. Administration of Ro 64-6198 did not significantly affect any of the variables under consideration. These results are summarized in Table 3.

\section{Discussion}

The present study yielded ethanol-induced aversive taste conditioning and ethanol anti-anxiety effects in infant and adolescent rats; ethanol locomotor activating effects and a moderate level of ethanol consumption ( $1 \mathrm{~g} / \mathrm{kg} / 2 \mathrm{~h}$, since the second day of test) in adolescent rats. In addition, ethanol increased the number of transfers between compartments during infancy, but did not increase time spent in the white, potentially stress-inducing, area of the LDB box. New information was that, in adolescent rats, activation of NOP receptors by the specific agonist Ro 64-6198 attenuated ethanolinduced anxiolysis and ethanol-induced behavioral stimulation, but did not affect ethanol-induced aversion or ethanol intake. 

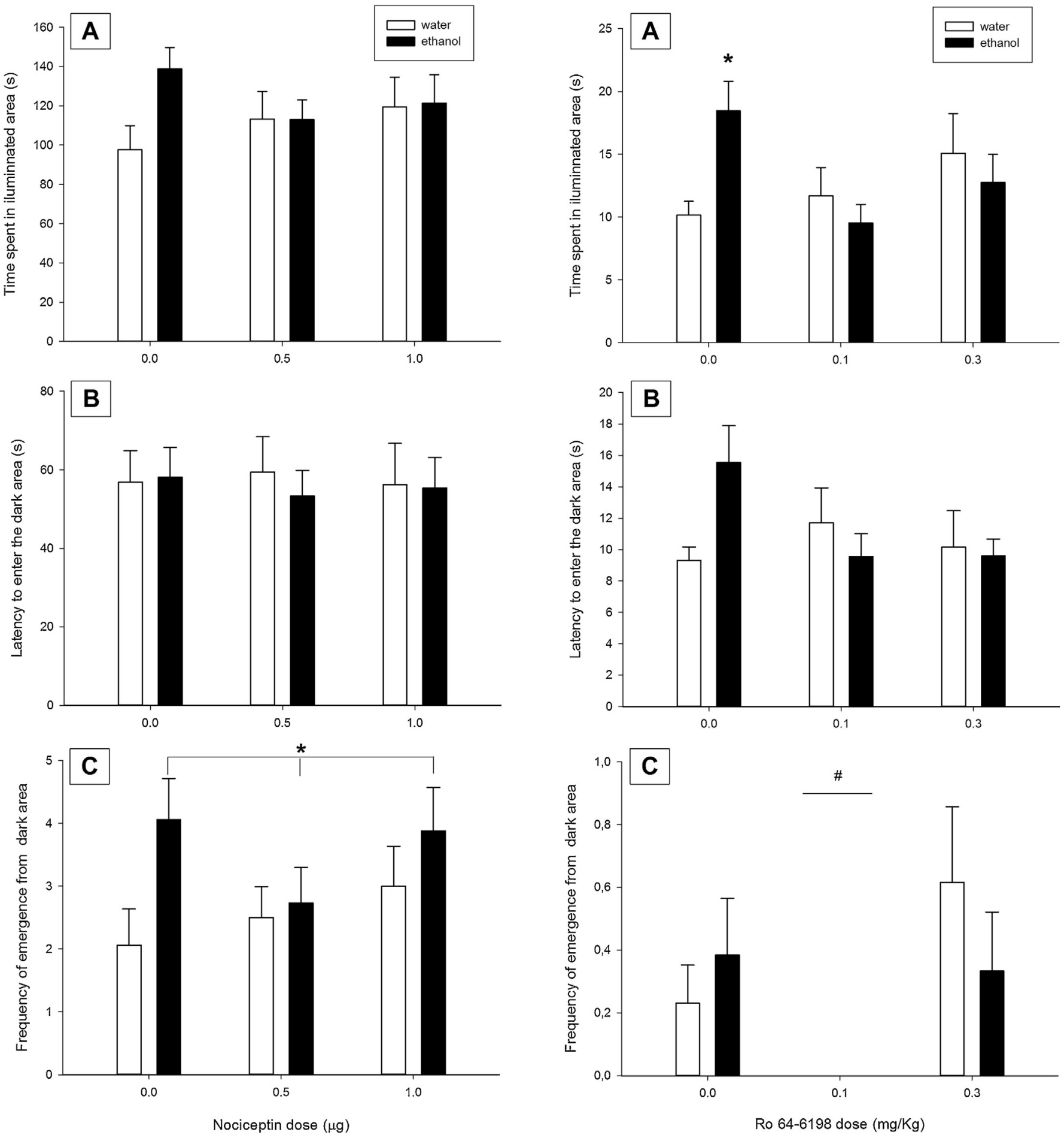

Fig. 1. Behavioral patterns of infant rats tested in a light-dark box as a function of nociceptin $(0.0,0.5$ or $1.0 \mu \mathrm{g})$ and ethanol administration $(0.0$ or $0.5 \mathrm{~g} / \mathrm{kg})$. Panel A depicts time spent (s) in the illuminated area; panel B represents the latency to enter (s) into the dark area and panel $\mathrm{C}$ depicts the frequency of emergences (i.e., exits) from the dark area. The asterisk $\left({ }^{*}\right)$ sign indicates significant differences between $0.5 \mathrm{~g} / \mathrm{kg}$ ethanol and the control group $(0.0 \mathrm{~g} / \mathrm{kg})$. Data has been collapsed across sex. Across variables, Sex did not exert a significant main effect nor was involved in significant interactions. Values represent mean \pm SEM.

Fig. 2. Behavioral patterns of adolescent rats tested in a light-dark box as a function of Ro 64-6198 $(0.0,0.1$ or $0.3 \mathrm{mg} / \mathrm{kg})$ and ethanol $(0.0$ or $0.5 \mathrm{~g} / \mathrm{kg})$ administration. Panel A depicts time spent (s) in the illuminated area; panel B represents the latency to enter (s) into the dark area and panel $C$ depicts the frequency of emergences (i.e., exits) from the dark area. The asterisk $\left(^{*}\right)$ sign indicates significant differences between group 0.0 Ro 64-6198 $+0.5 \mathrm{~g} / \mathrm{kg}$ ethanol and the remaining groups (except from group 0.3 Ro $64-6198+0.5 \mathrm{~g} / \mathrm{kg}$ ethanol; $p=0.07$ ). The pound (\#) sign indicates significant differences between the $0.1 \mathrm{mg} / \mathrm{kg}$ Ro 64-6198 treatment and the remaining Ro 64-6198 conditions. Data has been collapsed across sex. Across variables, Sex did not exert a significant main effect nor was involved in significant interactions Values represent mean \pm SEM. 


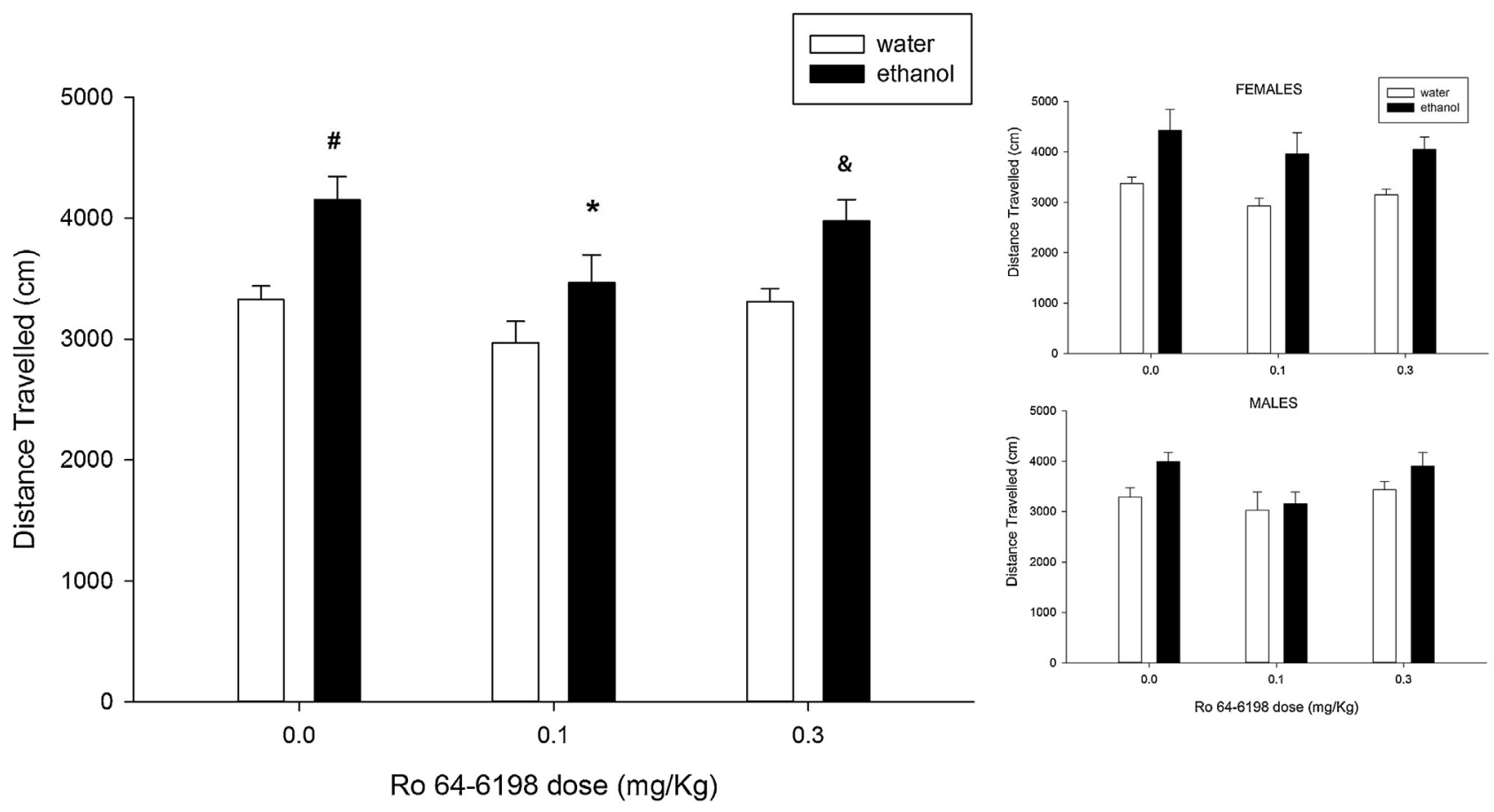

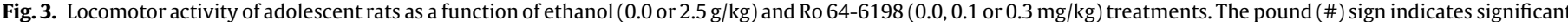

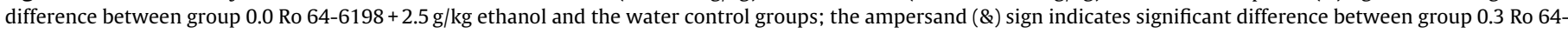

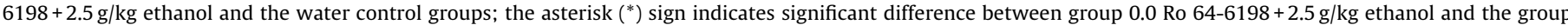

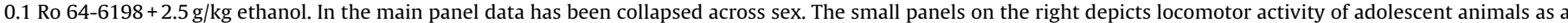
function of sex (females and males). Values represent mean \pm SEM.

Table 3

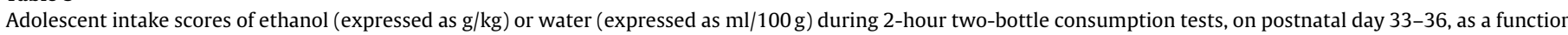

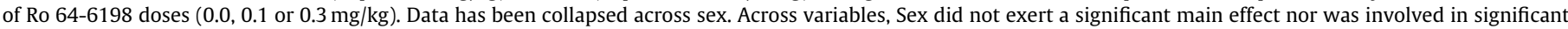
interactions. Values are expressed as mean \pm SEM.

\begin{tabular}{|c|c|c|c|c|c|}
\hline \multirow[t]{2}{*}{ Ro 64-6198 doses } & \multirow[t]{2}{*}{ Solutions consumed } & \multicolumn{4}{|c|}{ Days of consumption test } \\
\hline & & PD33 & PD34 & PD35 & PD36 \\
\hline \multirow{2}{*}{$0.0 \mathrm{mg} / \mathrm{kg}$} & Ethanol & $0.49 \pm 0.08$ & $0.77 \pm 0.12$ & $0.90 \pm 0.11$ & $1.10 \pm 0.11$ \\
\hline & Water & $2.68 \pm 0.58$ & $2.34 \pm 0.40$ & $3.26 \pm 0.47$ & $2.35 \pm 0.48$ \\
\hline \multirow{2}{*}{$0.1 \mathrm{mg} / \mathrm{kg}$} & Ethanol & $0.60 \pm 0.09$ & $0.91 \pm 0.11$ & $0.96 \pm 0.18$ & $0.86 \pm 0.16$ \\
\hline & Water & $1.86 \pm 0.38$ & $1.87 \pm 0.57$ & $3.04 \pm 0.58$ & $2.90 \pm 0.50$ \\
\hline \multirow{2}{*}{$0.3 \mathrm{mg} / \mathrm{kg}$} & Ethanol & $0.70 \pm 0.09$ & $1.17 \pm 0.14$ & $1.12 \pm 0.19$ & $1.22 \pm 0.16$ \\
\hline & Water & $1.71 \pm 0.38$ & $1.33 \pm 0.33$ & $2.77 \pm 0.50$ & $2.44 \pm 0.46$ \\
\hline
\end{tabular}

Analogous activation of NOP in preweanling rats by the natural ligand nociceptin did not alter ethanol-induced aversion or anxiolysis.

More in detail, Experiment 1 revealed that activation of the NOP receptor did not affect conditioned taste aversion by ethanol (measured as level of intake of an ethanol-paired flavor) in infant or adolescent animals. Previously, it has been observed that $\kappa$ receptors modulate responses to ethanol-paired flavors [12]. Yet, in that case, authors inquired on the modulation of conditioned taste preference and not conditioned taste aversion, as in the present study. To our knowledge, this is the first study to analyze NOP involvement in ethanol's aversive effects. As a function of the present results, it seems that NOP receptors do not modulate ethanol aversive effects during infancy or adolescence.

The results obtained in the LDB test revealed, in accordance with previous work [37], ethanol-induced anxiolysis in adolescent Wistar rats. We, however, were not able to reproduce these effects in preweanling rats, as it had been reported - although in the Sprague-Dawley strain - by Miranda-Morales [36]. In Experiment $2 a$, the administration of ethanol to the infants induced a significant increase in the frequency of emergence from the dark area, but did not significantly alter the remaining variables under analysis. Anxiolytics drugs (i.e., diazepam) enhance locomotion and exploratory behavior in the LDB (often measured via frequency of transfers from one compartment to the other), but also increase the time spent in the white area of the apparatus [44]. In the present study, we observed a trend for an ethanol-induced increase in time spent in the white area (see Fig. 1A, group $0.0 \mathrm{mg} / \mathrm{kg}$ Ro 64-6198; infant rats), yet this effect did not achieved significance. Other studies have also found similar discrepancies (i.e., treatment-induced changes in one measure but not in others) when using the LDB test (see [44]). The nociceptin treatment did not exert significant effects on the behavior of the infants in Experiment 2a.

On the other hand, adolescent subjects treated with the NOP agonist before ethanol (Experiment $2 \mathrm{~b}$ ) displayed significantly less time in the white area than animals treated with saline and ethanol. This indicates that activation of NOP receptors is effective in attenuating ethanol's anxiolytic effects at this age. This ethanol $\times$ NOP interaction was not the result of an independent action of the agonist (i.e., animals injected Ro 64-6198 and intubated with water behaved similarly to saline-injected animals), and was not observed in the other variables measured. Latency to enter into the dark area was not significantly affected by ethanol or Ro 64-6198 treatments, whereas frequency of emergence from the dark area was inhibited by Ro 64-6198 treatment but unaffected by ethanol treatment. As 
mentioned, it is not uncommon that a given treatment affects one, but not all, of the variables measured in an LDB test. A study [45] found that benzodiazepines increased the number of transitions between compartments, but did not affect time spent in each compartment. On the other hand, Costall et al. [46] found that increased exploratory behavior resulting from benzodiazepine administration was accompanied by greater time spent in the illuminated area, although the number of transitions between the two compartments remained unchanged. The latter results are congruent with the pattern found in Experiment $2 \mathrm{~b}$ : ethanol increased time spent in the illuminated area without changing the number of transitions between compartments. In addition, NOP activation by the administration of the $0.1 \mathrm{mg} / \mathrm{kg}$ Ro 64-6198 dose attenuated this effect of ethanol and significantly attenuated the number of transfer between compartments. This may help explain the inhibitory effect exerted by NOP activation on ethanol's activating effects, as observed during the LMA test.

The activation of NOP receptors attenuated the locomotor stimulating effects of ethanol in adolescents (Experiment 3). These results are in agreement with our previous studies indicating that central administration of nociceptin blocked the ethanol stimulating effect in infant rats [16]. The $0.1 \mathrm{mg} / \mathrm{kg}$ Ro 64-6198 dose attenuated ethanol's motor stimulating effects as well as the overall exploratory behavior of the rats in the LDB. Specifically, this dose induced a significant reduction in frequency of emergence from the dark area, both in ethanol and in vehicle-treated animals. It is possible to speculate, then, that the blockade of ethanol's stimulating effects is the result of a general inhibition of motor activity induced by the $0.1 \mathrm{mg} / \mathrm{kg}$ Ro 64-6198 dose. This possibility however, appears unlikely when considering that vehicle treated subjects exhibited similar motor activity during the LMA, regardless the dose of Ro 64-6198 received.

The study of the mechanisms underlying ethanol-mediated behavioral stimulation is relevant because of its possible mechanistic association with the reinforcing effects of drugs of abuse [47]. The $\mathrm{CRF}_{1}$ receptor modulates the development and expression of locomotor sensitization induced by ethanol in adults $[48,49]$. Moreover, a recent study indicated that blockade of $\mathrm{CRF}_{1}$ receptors eliminated ethanol-induced locomotor activity [50]. These authors postulate that stress is a critical variable for the emergence of ethanol-induced locomotor activation and that this interaction is mediated by the CRF system [50]. Several studies (e.g., [15]) postulate a possible interaction of NOP and CRF receptors, in which nociceptin would act as an antagonist within the CRF receptor system. Recent work tested this hypothesis in Marchigian Sardinian alcohol-preferring ( $\mathrm{msP}$ ) strain of rats, which exhibit an elevated expression of the $\mathrm{CRF}_{1}$ receptor in numerous brain areas. This increase has been identified as the molecular substrate of the anxious, stress-sensitive phenotype and the high alcohol preference of this strain of rats [51]. In this strain (compared with heterogeneous Wistar rats) the NOP receptor messenger RNA expression and binding is upregulated across most brain regions and this is accompanied by a substantial increase in agonist-induced NOP receptor signaling in almost all the brain areas investigated [52]. On the basis of these findings the authors propose that up-regulation of the NOP system occurs in msP rats in response to and in an attempt to compensate the up-regulation of CRF1 receptors in this line of rats [52].

In the present study, the $0.1 \mathrm{mg} / \mathrm{kg}$, but not the $0.3 \mathrm{mg} / \mathrm{kg}$, Ro 64-6198 dose was effective in attenuating ethanol's anxiolytic and stimulating effects, in the adolescent rats. It is thus possible that a U-shaped function accounts for the effects of this NOP agonist on ethanol consequences. Previous studies conducted in adult rats, nonetheless, showed that administration of Ro 64-6198 caused a dose-dependent reduction in ethanol self-administration [22], as well as in the acquisition, expression, and reinstatement of ethanol-induced conditioned place preference [53]. Both studies employed Ro 64-6198 at doses similar (i.e., 0.1, 0.3 and $1.0 \mathrm{mg} / \mathrm{kg}$ ) to those used in the present study. In contrast, the natural ligand nociceptin seems to exhibit biphasic effects [54], with low and high doses stimulating and inhibiting locomotion, respectively. Also noteworthy is that other researchers indicated that the administration of Ro 64-6198 at doses $>0.3 \mathrm{mg} / \mathrm{kg}$ can induces anxiolysis [55]. It seems, therefore, plausible to postulate that, in Experiment $2 \mathrm{~b}$, a subthreshold anxiolytic effect of the $0.3 \mathrm{mg} / \mathrm{kg}$ Ro $64-6198$ dose summed to the anxiolytic effect of ethanol and resulted in a net effect that opposed the blocking effect observed after $0.1 \mathrm{mg} / \mathrm{kg}$ Ro 64-6198. The rationale underlying this explanation can also be applied to effects of ethanol on motor activity (Experiment 3). It is known that anxiolytic drugs increase exploration of a novel environment. The activating effect of $2.5 \mathrm{~g} / \mathrm{kg}$ ethanol could have added up to the subthreshold anxiolytic effect of $0.3 \mathrm{mg} / \mathrm{kg}$ Ro dose. Therefore, this dose did not attenuate motor activation, but instead helped maintain the activating effect of the drug.

Activation of NOP receptors did not modify ethanol intake patterns during adolescence, a result consistent with previous findings in infant [16] and adult [52] heterogeneous rats. The studies in which nociceptin suppressed ethanol drinking, employed the msP strain of rats, which were genetically selected for ethanol preference [21]. Economidou and colleagues postulate that the excessive ethanol intake of msP rats is a result of an ethanol-induced amelioration of their anxious phenotype [52]. Therefore, it seems reasonable to hypothesize that the ability of NOP agonists to attenuate ethanol intake in msP rats is a consequence of the agonists inhibiting (as observed in the present study) the anxiolytic effects of ethanol. A main difference between this study and those conducted in adults, is that the adults were not under fluid restriction before test. In addition, msP and Wistar adult rats tested for the modulatory effect of NOP on ethanol intake received the NOP treatment after weeks of exposure to $10 \%$ ethanol [52]. Adolescents evaluated in the present study were naïve to ethanol at the moment of the test. The present results, along with those observed in Miranda-Morales et al. [16], suggest that the mechanism by which genetically heterogeneous infant and adolescent rats drink ethanol may not involve negative reinforcement (as it is assumed for msP rats). Instead, ethanol drinking in these so-called "developing animals" may be regulated by ethanol's positive reinforcing consequences.

The main results of this study are that NOP receptors seem to modulate ethanol's anxiolytic and activating affects during adolescence. We suggest that this modulatory role could be related to a functional antagonism of $\mathrm{CRF}_{1}$ receptors. This is of course just a hypothesis, and more work should be devoted to analyze this possible interaction. In addition, we hypothesized that ethanol drinking during early ontogeny is regulated by the positive reinforcing consequences of the drug. The knowledge derived from this study could help understand the mechanism underlying ethanol-induced anxiolysis, behavioral stimulation and, ultimately, predisposition for problematic ethanol intake.

\section{Acknowledgments}

This work was supported by grants PICT 2012 and PIP 2012 to R.M.P. and by a post-doctoral fellowship awarded by CONICET to R.S.M.M. The authors would like to thank Dr. Eric Prinssen (F. Hoffmann-La Roche Ltd, Pharma Preclinical Research, Basel, Switzerland) for generously providing Ro 64-6198.

\section{References}

[1] Herz A. Endogenous opioid system and alcohol addiction. Psychopharmacology 1997;129:99-111. 
[2] Gianoulakis C. Endogenous opioids and addiction to alcohol and other drugs of abuse. Curr Top Med Chem 2009;9:999-1015.

[3] New DC, Wong YH. The ORL1 receptor: molecular pharmacology and signalling mechanisms. Neurosignals 2002;11:197-212.

[4] Froehlich JC. Opioid peptides. Alcohol Health Res World 1997;21:132-6.

[5] Spear NE, Molina JC. Fetal or infantil exposure to alcohol promotes ethanol ingestion in adolescence and adulthood: a theoretical review. Alcohol Clin Exp Res 2005;25:909-29.

[6] Doremus TL, Brunell SC, Rajendran P, Spear LP. Factors influencing elevated ethanol consumption in adolescent relative to adult rats. Alcohol Clin Exp Res 2005;29:1796-808.

[7] Chotro MG, Arias C. Prenatal exposure to ethanol increases ethanol consumption: a conditioned response. Alcohol 2003;30:19-28.

[8] Miranda-Morales RS, Molina JC, Spear NE, Abate P. Participation of the endogenous opioid system in the acquisition of a prenatal ethanol-related memory: effects on neonatal and preweanling responsiveness to ethanol. Physiol Behav 2010;101:153-60.

[9] Diaz-Cenzano E, Gaztanaga M, Gabriela Chotro M. Exposure to ethanol on prenatal days 19-20 increases ethanol intake and palatability in the infant rat: involvement of kappa and mu opioid receptors. Dev Psychobiol 2014; $56: 1167-78$.

[10] Nizhnikov ME, Varlinskaya EI, Spear NE. The central reinforcing properties of ethanol are mediated by endogenous opioid systems: effects of mu and kappa opioid antagonists. Rev Argent Cienc Comport 2009;1:1-12.

[11] Arias C, Molina JC, Spear NE. Differential role of micro, delta and kappa opioid receptors in ethanol-mediated locomotor activation and ethanol intake in preweanling rats. Physiol Behav 2010;99:348-54.

[12] Pautassi RM, Nizhnikov ME, Acevedo MB, Spear NE. Early role of the kappa opioid receptor in ethanol-induced reinforcement. Physiol Behav 2012;105:1231-41.

[13] Nizhnikov ME, Pautassi RM, Carter JM, Landin JD, Varlinskaya EI, Bordner KA, et al. Brief prenatal ethanol exposure alters behavioral sensitivity to the kappa opioid receptor agonist (U62,066E) and antagonist (Nor-BNI) and reduces kappa opioid receptor expression. Alcohol Clin Exp Res 2014;38:1630-8.

[14] Miranda-Morales RS, Spear NE, Nizhnikov ME, Molina JC, Abate P. Role of mu, delta and kappa opioid receptors in ethanol-reinforced operant responding in infant rats. Behav Brain Res 2012;234:267-77.

[15] Ciccocioppo R, Economidou D, Fedeli A, Massi M. The nociceptin/orphanin $\mathrm{FQ} / \mathrm{NOP}$ receptor system as a target for treatment of alcohol abuse: a review of recent work in alcohol-preferring rats. Physiol Behav 2003;79:121-8.

[16] Miranda-Morales RS, Nizhnikov ME, Waters DH, Spear NE. Participation of the nociceptin/orphanin FQ receptor in ethanol-mediated locomotor activation and ethanol intake in preweanling rats. Behav Brain Res 2013;245:137-44.

[17] Neal Jr CR, Akil H, Watson Jr SJ. Expression of orphanin FQ and the opioid receptor-like (ORL1) receptor in the developing human and rat brain. J Chem Neuroanat 2001;22:219-49.

[18] Reinscheid RK, Nothacker HP, Bourson A, Ardati A, Henningsen RA, Bunzow JR, et al. Orphanin FQ: a neuropeptide that activates an opioidlike G proteincoupled receptor. Science 1995;270:792-4.

[19] Martin-Fardon R, Ciccocioppo R, Massi M, Weiss F. Nociceptin prevents stress-induced ethanol- but not cocaine-seeking behavior in rats. Neuroreport 2000;11:1939-43.

[20] Ciccocioppo R, Polidori C, Antonelli L, Salvadori S, Guerrini R, Massi M. Pharmacological characterization of the nociceptin receptor which mediates reduction of alcohol drinking in rats. Peptides 2002;23:117-25.

[21] Ciccocioppo R, Economidou D, Fedeli A, Angeletti S, Weiss F, Heilig M, et al. Attenuation of ethanol self-administration and of conditioned reinstatement of alcohol-seeking behaviour by the antiopioid peptide nociceptin/orphanin FQ in alcohol-preferring rats. Psychopharmacology (Berl) 2004;172:170-8.

[22] Kuzmin A, Kreek MJ, Bakalkin G, Liljequist S. The nociceptin/orphanin FQ receptor agonist Ro 64-6198 reduces alcohol self-administration and prevents relapse-like alcohol drinking. Neuropsychopharmacology 2007;32:902-10.

[23] Ubaldi M, Bifone A, Ciccocioppo R. Translational approach to develop novel medications on alcohol addiction: focus on neuropeptides. Curr Opin Neurobiol 2013;23:684-91.

[24] Sakoori K, Murphy NP. Central administration of nociceptin/orphanin FQ blocks the acquisition of conditioned place preference to morphine and cocaine, but not conditioned place aversion to naloxone in mice. Psychopharmacology (Berl) 2004;172:129-36.

[25] Kotlinska J, Wichmann J, Legowska A, Rolka K, Silberring J. Orphanin FQ/nociceptin but not Ro 65-6570 inhibits the expression of cocaine-induced conditioned place preference. Behav Pharmacol 2002;13:229-35.

[26] Kotlinska J, Rafalski P, Biala G, Dylag T, Rolka K, Silberring J. Nociceptin inhibits acquisition of amphetamine-induced place preference and sensitization to stereotypy in rats. Eur J Pharmacol 2003;474:233-9.

[27] Noal RB, Menezes AM, Araujo CL, Hallal PC. Experimental use of alcohol in early adolescence: the 11-year follow-up of the 1993 Pelotas (Brazil) birth cohort study. Cad Saude Publica 2010;26:1937-44.

[28] Pilatti A, Godoy JC, Brussino S, Pautassi RM. Underage drinking: prevalence and risk factors associated with drinking experiences among Argentinean children. Alcohol 2013;47:323-31.
[29] Donovan JE, Molina BS. Types of alcohol use experience from childhood through adolescence. J Adolesc Health 2013;53:453-9.

[30] Acevedo MB, Pautassi RM, Spear NE, Spear LP. Age-dependent effects of stress on ethanol-induced motor activity in rats. Psychopharmacology (Berl) 2013;230:389-98.

[31] National Research Council (US). Committee for the Update of the Guide for the Care and Use of Laboratory Animals. Guide for the Care and Use of Laboratory Animals. 8th edition Washington (DC): National Academies Press (US); 2011.

[32] Petrov ES, Varlinskaya EI, Smotherman WP. Endogenous opioids and the first suckling episode in the rat. Dev Psychobiol 1998;33:175-83.

[33] Varlinskaya EI, Petrov ES, Smotherman WP. Classical conditioning in the fetal rat: reinforcing properties of dynorphin a (1-13). Behav Neurosci 1996;110:154-67.

[34] Calo G, Rizzi A, Bigoni R, Guerrini R, Salvadori S, Regoli D. Pharmacological profile of nociceptin/orphanin FQ receptors. Clin Exp Pharmacol Physiol 2002;29(3):223-8.

[35] Goeldner C, Spooren W, Wichmann J, Prinssen EP. Further characterization of the prototypical nociceptin/orphanin FQ peptide receptor agonist Ro 64-6198 in rodent models of conflict anxiety and despair. Psychopharmacology (Berl) 2012;222:203-14.

[36] Miranda-Morales RS, Nizhnikov ME, Waters DH, Spear NE. New evidence of ethanol's anxiolytic properties in the infant rat. Alcohol 2014;48:367-74.

[37] Acevedo MB, Nizhnikov ME, Molina JC, Pautassi RM. Relationship between ethanol-induced activity and anxiolysis in the open field, elevated plus maze, light-dark box, and ethanol intake in adolescent rats. Behav Brain Res 2014;265:203-15.

[38] Acevedo MB, Molina JC, Nizhnikov ME, Spear NE, Pautassi RM. High ethanol dose during early adolescence induces locomotor activation and increases subsequent ethanol intake during late adolescence. Dev Psychobiol 2010;52:424-40.

[39] Anderson RI, Varlinskaya EI, Spear LP. Ethanol-induced conditioned taste aversion in male Sprague-Dawley rats: impact of age and stress. Alcohol Clin Exp Res 2010;34(12):2106-15.

[40] Abate P, Spear NE, Molina JC. Fetal and infantile alcohol-mediated associative learning in the rat. Alcohol Clin Exp Res 2001;25(7):989-98.

[41] Pautassi RM, Godoy JC, Spear NE, Molina JC. Early responsiveness to stimuli paired with different stages within the state of alcohol intoxication. Alcohol Clin Exp Res 2002;26(5):644-54.

[42] Ponce LF, Pautassi RM, Spear NE, Molina JC. Ethanol-mediated operant learning in the infant rat leads to increased ethanol intake during adolescence. Pharmacol Biochem Behav 2008;90:640-50.

[43] Pepino MY, Abate P, Spear NE, Molina JC. Heightened ethanol intake in infant and adolescent rats after nursing experiences with an ethanol-intoxicated dam. Alcohol Clin Exp Res 2004;28:895-905.

[44] Bourin M, Hascoët M. The mouse light/dark box test. Eur J Pharmacol 2003;463(1-3):55-65.

[45] Crawley JN, Goodwin FK. Preliminary report of a simple animal behaviour for the anxiolytic effects of benzodiazepines. Pharmacol Biochem Behav 1980;13:167-70.

[46] Costall B, Jones BJ, Kelly ME, Naylor RJ, Tomkins DM. Exploration of mice in a black and white box: validation as a model of anxiety. Pharmacol Biochem Behav 1989;32:777-85.

[47] Wise RA, Bozarth MA. A psychomotor stimulant theory of addiction. Psychol Rev 1987;94:469-92.

[48] Fee JR, Sparta DR, Picker MJ, Thiele TE. Corticotropin releasing factor-1 receptor antagonist, CP-154,526, blocks the expression of ethanol-induced behavioral sensitization in DBA/2J mice. Neuroscience 2007;150:14-21.

[49] Pastor R, McKinnon CS, Scibelli AC, Burkhart-Kasch S, Reed C, Ryabinin AE, et al. Corticotropin-releasing factor-1 receptor involvement in behavioral neuroadaptation to ethanol: a urocortin1-independent mechanism. Proc Natl Acad Sci U S A 2008;105:9070-5.

[50] Arias C, Solari AC, Mlewski EC, Miller S, Haymal B, Spear NE, et al. Social isolation and stress related hormones modulate the stimulating effect of ethanol in preweanling rats. Behav Brain Res 2010;211:64-70.

[51] Hansson AC, Cippitelli A, Sommer WH, Fedeli A, Bjork K, Soverchia L, et al. Variation at the rat Crhr1 locus and sensitivity to relapse into alcohol seeking induced by environmental stress. Proc Natl Acad Sci U S A 2006;103: 15236-41.

[52] Economidou D, Hansson AC, Weiss F, Terasmaa A, Sommer WH, Cippitelli A, et al. Dysregulation of nociceptin/orphanin FQ activity in the amygdala is linked to excessive alcohol drinking in the rat. Biol Psychiatry 2008;64:211-8.

[53] Kuzmin A, Sandin J, Terenius L, Ogren SO. Acquisition, expression, and reinstatement of ethanol-induced conditioned place preference in mice: effects of opioid receptor-like 1 receptor agonists and naloxone. J Pharmacol Exp Ther 2003;304:310-8.

[54] Kuzmin A, Sandin J, Terenius L, Ogren SO. Evidence in locomotion test for the functional heterogeneity of ORL-1 receptors. Br J Pharmacol 2004;141: 132-40.

[55] Jenck F, Wichmann J, Dautzenberg FM, Moreau J-L, Ouagazzal AM, Martin JR, et al. A synthetic agonist at the orphanin FQ/nociceptin receptor ORL1: anxiolytic profile in the rat. Proc Natl Acad Sci U S A 2000;97:4938-43. 